\title{
Development of consensus based national antimicrobial stewardship competencies for UK undergraduate healthcare professional education
}

Article

Accepted Version

Creative Commons: Attribution-Noncommercial-No Derivative Works 4.0

Courtenay, M., Lim, R., Castro-Sanchez, E., Deslandes, R., Hodson, K., Morris, G., Reeves, S., Weiss, M., AshiruOredope, D., Bain, H., Black, A., Bosanquet, J., Cockburn, A., Duggan, C., Fitzpatrick, M., Gallagher, R., Grant, D., McEwan, J., Reid, N., Sneddon, J., Stewart, D., Tonna, A. and White, P. (2018) Development of consensus based national antimicrobial stewardship competencies for UK undergraduate healthcare professional education. The Journal of Hospital Infection, 100 (3). pp. 245-256. ISSN 0195-6701 doi: https://doi.org/10.1016/j.jhin.2018.06.022 Available at https://centaur.reading.ac.uk/77937/

It is advisable to refer to the publisher's version if you intend to cite from the work. See Guidance on citing.

To link to this article DOI: http://dx.doi.org/10.1016/j.jhin.2018.06.022

Publisher: Healthcare Infection Society

All outputs in CentAUR are protected by Intellectual Property Rights law, 
including copyright law. Copyright and IPR is retained by the creators or other copyright holders. Terms and conditions for use of this material are defined in the End User Agreement.

\section{www.reading.ac.uk/centaur}

\section{CentAUR}

Central Archive at the University of Reading

Reading's research outputs online 


\section{Development of consensus based national antimicrobial stewardship competencies for UK}

undergraduate healthcare professional education

Molly Courtenay ${ }^{1 *}$, Rosemary Lim, ${ }^{2}$ Enrique Castro-Sanchez ${ }^{3}$, Rhian Deslandes ${ }^{4}$, Karen Hodson ${ }^{4}$, Gary Morris ${ }^{1,5}$, Scott Reeves ${ }^{6}$, Marjorie Weiss ${ }^{4}$, Diane Ashiru-Oredope ${ }^{7}$, Heather Bain ${ }^{8}$, Adam Black $^{9}$, Joanne Bosanquet ${ }^{7}$, Alison Cockburn ${ }^{10}$, Catherine Duggan ${ }^{11}$, Matthew Fitzpatrick ${ }^{12}$, Rose Gallagher ${ }^{13}$, Daniel Grant, ${ }^{2}$ Jo McEwen, ${ }^{14}$ Nicholas Reid, ${ }^{15}$ Jacqueline Sneddon, ${ }^{16}$ Derek Stewart, ${ }^{17}$ Antonella Tonna, ${ }^{17}$ Pip White ${ }^{18}$

${ }^{1}$ School of Health Sciences, Cardiff University, Cardiff, CF24 OAB, UK, ${ }^{2}$ Reading School of Pharmacy, University, Reading, RG6 6AP, UK, ${ }^{3}$ NIHR Health Protection Unit in Healthcare Associated Infection and Antimicrobial Resistance, Imperial College London, London, W12 ONN, UK, ${ }^{4}$ School of Pharmacy and Pharmaceutical Sciences, Cardiff University, Cardiff, CF24 $\mathrm{OAB}, \mathrm{UK}{ }^{5} \mathrm{Hyw}$ el Dda University Health Board, Carmarthen, SA31 2AF, UK, ${ }^{6}$ Faculty of Health, Social Care and Education, Kingston \& St George's, University of London, London, SW17 OBE, UK, ${ }^{7}$ Antimicrobial Resistance Programme Public Health England, London, SE1 8UG, UK, ${ }^{8}$ School of Nursing and Midwifery, Robert Gordon University, Aberdeen AB10-7QG, UK, ${ }^{9}$ Faculty of Nursing, Midwifery \& Palliative Care, King's College London, London, SE1 8WA, UK, ${ }^{10}$ Regional Infectious Diseases Unit, Western General Hospital, Edinburgh,EH4-2XU, UK, ${ }^{11}$ Royal Pharmaceutical Society, London, E1W 1AW, ${ }^{12}$ College of Podiatry, London, SE1 2EW, UK, ${ }^{13}$ Royal College of Nursing, London W1G ORN, UK, ${ }^{14} \mathrm{NHS}$ Tayside, Dundee DD1 9SY, UK, ${ }^{15}$ Public Health Wales, Cardiff, CF10 4BZ, UK, ${ }^{16}$ Healthcare Improvement Scotland, Glasgow, G1 2NP, UK, ${ }^{17}$ School of Pharmacy and Life Sciences, Robert Gordon University, Aberdeen AB10-7QG, UK, ${ }^{18}$ Chartered Society of Physiotherapy, London WC1R 4ED, UK

Antimicrobial stewardship competencies 
*Corresponding author:

Molly Courtenay

Email: courtenaym@cardiff.ac.uk

Tel: 02920688566 


\section{STRUCTURED SUMMARY}

Background: Healthcare professionals are involved in an array of patient and medicine related stewardship activities, for which an understanding and engagement with antimicrobial stewardship is important. Undergraduate education provides an ideal opportunity to prepare healthcare professionals for these roles and activities.

Aim: To provide United Kingdom national consensus on a common set of antimicrobial stewardship competencies appropriate for undergraduate healthcare professional education

Methods: A modified Delphi approach comprising two on-line surveys delivered to a United Kingdom national panel of twenty-one individuals reflecting expertise in prescribing and medicines management with regards to the education and practice of nurses and midwives, pharmacists, physiotherapists and podiatrists; and antimicrobial prescribing and stewardship. Data collection took place between October and December 2017.

Findings: A total of 21 participants agreed to become members of the expert panel, of whom 19 (90\%) completed round 1 questionnaire, and 17 (89\%) completed round 2. Panelists reached a consensus, with consistent high levels of agreement reached, on 6 overarching competency statements (sub divided into 6 domains), and 55 individual descriptors essential for antimicrobial stewardship by healthcare professionals. 
Conclusion: Given the consistently high levels of agreement reached on competency statements and their associated descriptors, this competency framework should be used to direct undergraduate healthcare professional education, and those working in new clinical roles to support healthcare delivery, with regards to the array of activities for which an understanding and engagement with AMS is important. Although the competencies target undergraduate education, they can also be used for continuing education.

\section{Keywords}

Antimicrobial stewardship, competencies, undergraduate healthcare professional education, modified Delphi 


\section{INTRODUCTION}

Multi-drug resistant infections are one of the greatest threats to human health [1]. Direct consequences of infection with resistant micro-organisms include longer illnesses, increased mortality, prolonged stays in hospital, loss of protection for patients undergoing operations and other medical procedures, and increased costs [1]. Antimicrobial resistance (AMR) is responsible for an estimated 25,000 deaths and $€ 1.5$ billion in extra healthcare costs every year in the European Union (EU) alone [2].

Antimicrobial resistance is a multifaceted problem requiring multifactorial interventions to prevent its emergence and further spread [3]. Antimicrobial stewardship (AMS) requires an interprofessional approach that involves collaboration between different healthcare providers [3-4], to ensure the optimal selection, dosage, and duration of antimicrobial treatment that results in the best clinical outcome for the treatment or prevention of infection, with minimal toxicity to the patient and minimal impact on subsequent resistance [5].

The education of undergraduate healthcare professional students on AMS has been identified as a key activity for the containment of antimicrobial resistance [6]. However, a cross-sectional survey of undergraduate programmes in human and veterinary medicine, dentistry, pharmacy and nursing in the United Kingdom (UK) [7], identified that students receive disparate stewardship education. Only $36.3 \%$ of programmes surveyed, were reported to include all the 
recommended AMS principles. These researchers concluded that in order to strengthen the concept of AMS in undergraduate healthcare professional education, there is a need to adopt a comprehensive approach with standardised content. Such an approach has been adopted by infectious disease training programmes in the US [8], with the development of a national stewardship curriculum, specifically to address gaps concerning comprehensive and structured educational resources for AMS training.

Over recent years there has been increasing emphasis upon competency-based education (CBE). CBE focuses upon the capacity of the learner to successfully carry out tasks in the real world, rather than the learner's ability to absorb and recite content [9]. CBE recognizes that quality of care is not improved simply by accumulating and disseminating the best available evidence [10] but instead, with the increasing emphasis on person-centred care, it is necessary for clinicians to respond to patients' needs in a compassionate, knowledgeable, and coordinated fashion [11] This shift toward assessment of quality and outcomes of care has meant that both professional and interprofessional curricular content is now associated with competencies [12].

Antimicrobial prescribing and stewardship post-registration competencies, designed to complement the Royal Pharmaceutical Society (RPS) generic competency framework for all prescribers [13], and improve the quality of antimicrobial treatment and stewardship and so reduce the risks of inadequate, inappropriate and ill-effects of treatment, have been developed for UK prescribers [14]. This includes doctors and dentists (who are able to prescribe upon initial 
registration) and other registered healthcare professionals including pharmacists, nurses, midwives, and allied health professionals (including physiotherapists, podiatrists, radiographers), who can prescribe after completing an additional regulated post-registration prescribing programme [15]. However, not all healthcare professionals go onto prescribe, but may well be involved in various patient and medicine related stewardship activities, and therefore an understanding and engagement with local AMS programmes is important. These activities may include medicines management tasks, administration of antibiotics, and monitoring of patients for effectiveness of treatment and adverse effects. Undergraduate education provides an important opportunity to prepare healthcare professionals for these activities. Standardised AMS principles [16], and AMS competencies for registered practitioners working at an advanced level [17], exist, and professional standards for undergraduate healthcare professional students [18-21] reflect some of the knowledge, skills and behaviours relevant to AMS. However, specific competencies designed to address the spectrum of AMS activities have not been established within this context. Additionally, the gradual implementation of new roles in the UK, such as Nursing Associates [22] and Physicians Associates [23], to support the delivery of healthcare, are responsible for delivering direct person or patient care. This is likely to include tasks related to medication management and broader AMS approaches such as the prevention of infection, therefore training will be mainly practical and 'hands-on', and subsequently requires consistent approaches to AMS activities. 
It is increasingly recognised that collaboration and teamwork between healthcare professionals are necessary to improve the quality and safety of health care [24]. Interprofessional education is important if a workforce is to practice collaboratively [25] and this resonates with the learning needs associated with AMS $[3-4,7]$. Within an interprofessional team delivering person-centered care, each profession will carry out roles that require both common knowledge and specific educational content to support achieving AMS competencies in a manner consistent with each profession's scope, emphasis, and role in health care. Therefore, to help bridge the gap between AMS and the skills, knowledge, and values of the interprofessional health care team, this research was undertaken to provide UK national consensus on a common set of AMS competencies appropriate for undergraduate healthcare professional education, designed to address the various patient and medicine related stewardship activities in which healthcare professionals are involved. Such competencies will help to standardise curricula and so boost the impact of AMS education and improve clinical practice.

\section{METHODS}

\section{Ethical consideration}

Ethical approval for the study was provided by the School of Healthcare Sciences Research Governance and Ethics Committee, Cardiff University (Reference number 427). 


\section{Design}

The study adopted a Delphi technique. This technique, a commonly used formal consensus method in health and social care research [26], uses a series of data collection rounds (typically two or three), to gather the opinions and judgments of a panel of experts on the topic of interest. Benefits of this technique are the ability to include large numbers of participants with a broad range of expertise, who are geographically dispersed, to derive consensus [26].

Round one of a classic Delphi survey involves item generation by use of an open-ended questionnaire, from which subsequent questionnaires are then developed [27-28]. However, a comprehensive list of competencies, informed by available prescribing and stewardship competency frameworks [13-14], AMS principles [16], evidence of the key AMS principles delivered on undergraduate health professional education programmes [7], and interprofessional competencies [29] replaced the classic round 1 survey i.e. a modified Delphi approach [26]. The use of a modified Delphi has been reported to be an appropriate option if pre-existing information is available [30]. These competencies, reported previously [31], adopted an integrated approach [32-33], and comprised overarching competency statements (sub divided into 6 domains) representing the knowledge, skills, attitudes, and values that shape the judgements essential for AMS, and 51 individual descriptors, designed to reflect the level of experience of the learner and type of practice setting (see Figure 1). The domains included infection prevention and control (16 descriptors), antimicrobials and antimicrobial resistance (4 descriptors), the diagnosis of infection and the use of antimicrobials (14 descriptors), 
antimicrobial prescribing practice (5 descriptors), person centred care (5 descriptors), and interprofessional collaborative practice (7 descriptors).

Insert Figures 1 about here

\section{Recruitment}

The Delphi technique employs 'experts' as panel members as opposed to a random sample representative of the target population. As there is no agreement as to what constitutes an 'expert' [34], it is recommended that explicit criteria are used to include participants in a study [35]. 'Expert' in this study was defined as; individuals reflecting expertise in prescribing and medicines management with regards to the education and practice of healthcare professionals; and antimicrobial prescribing and stewardship.

\section{Identification of expert panel members}

Purposive and snowball sampling methods were used to recruit expert panel members across countries within the UK. Using purposive methods, individuals in Royal Colleges and Societies and national groups and organisations who fulfilled the 'Expert' criteria were identified and contacted by the researchers. This included the Nursing and Midwifery Council (NMC), the Chartered Society of Physiotherapy, the Scottish Antimicrobial Prescribing Group, the Royal College of Nursing (RCN), Public Health England (PHE), Public Health Wales (PHW), the Royal Pharmaceutical Society (RPS), Health and Care Professions Council (HCPC), College of Podiatry, and the Society of Chiropodists and Podiatrists. Individuals who fulfilled 'Expert' criteria were 
also identified from the literature that was used to inform the pre-defined list of domains and descriptors to be used in the round one survey. Participants identified using these methods, then referred researchers to other potential participants i.e. snowball sampling.

\section{Sample size}

There is a lack of agreement as to the optimum number of participants to include on a Delphi panel [26], and it is recommended that sample size is dependent upon what is being investigated, the complexity of the problem, the homogeneity or heterogeneity of the sample, and availability of resources [26]. As participants were relatively homogenous, in-line with sample size recommendations for a homogenous sample i.e. around 15 participants [36], we aimed to recruit between 15-20 participants, and all those who expressed an interest to participate and fulfilled our 'expert' definition, were included.

\section{Recruitment procedure}

Twenty-one individuals fulfilled the expert criteria and expressed an interest to take part. Each was sent a Participant Information Sheet by email, and provided with the opportunity to address any queries they may have had, with a researcher. All twenty-one individuals agreed to participate. Completion of consensus survey questionnaires provided implied consent to participate.

\section{Data collection}


The survey was conducted across two rounds. Bristol Online Survey (BOS) - a tool for creating web surveys-was used to develop each round of the on-line questionnaire survey. Following confirmation of participation, and on a specified date, participants were sent an email (containing a link to on-line survey 1 and subsequently survey 2 ) inviting them to participate. Follow-up reminder emails were sent at one-week intervals. The survey was open for 3 weeks in each round. Data collection took place between October and December 2017.

First round questionnaire

The pre-defined competency statements and their associated descriptors formed the content of the first round of the Delphi survey. Participants were asked to use a 6 point Likert scale ( $1=$ not at all important to $6=$ extremely important) to rate each descriptor with regards to the extent to which they felt it was important. At the end of each domain, an open-ended question invited panel members to provide their interpretation and feedback, and to identify any additional descriptors they thought were missing.

\section{Second round questionnaire}

The round 2 questionnaire was administered in the same way as round one. However, only panel members who had completed round one were invited to participate. Following analysis of the first round, and prior to round 2, a report was circulated to participants detailing the quantitative results of the first Delphi round and inviting interpretation and feedback. Only descriptors for which there was a lack of agreement, descriptors that were amended in the light of qualitative 
feedback, and additional descriptors identified by panel members, were included in the second round questionnaire. See Figure 2 for a summary of the Delphi process.

Insert Figure 2 about here

\section{Data analysis}

Median scores and interquartile ranges (IQRs) were calculated for responses to each descriptor, in order to characterise the answer category above and below which $50 \%$ of the answers fell. IQRs were used to represent the spread of the data and to assess the level of consensus per question. Although there is no agreement on the best method used to determine consensus, a systematic review including 80 Delphi studies [37] identified the most frequently used method to achieve consensus was median scores and IQRs, and this method is considered robust [38]. Consistent with previous studies [39-40], 'responses where the median was equal to or higher than 5 (i.e. a high level of agreement that participants viewed it as important) with a small IQR (less than or equal to 1.5), were considered important descriptors that had reached consensus across expert panel members. Content analysis [41] was used to explore qualitative responses.

\section{RESULTS}


Of the 21 participants who agreed to take part, 19 (90\%) completed round 1 questionnaire, and 17 (89\%) completed round 2 (see Table 1 for Expert Panel details).

Insert Table I about here

\section{Round 1 survey results}

Of the nineteen expert panel members who responded to the round one survey, there were high levels of agreement for 50 of the 51 included descriptors with medians in the strong range of agreement (5-6 on the 6 point Likert scale) (see Table 2). The descriptor 'Discuss the use of rapid point-of-care diagnostic testing in infection diagnosis' was viewed as less important (4.5 on the 6 point Likert scale). The strength of agreement was high for 47 Descriptors (IQR less than or equal to 1.5) but lower for 4 descriptors including; 'Describe the concepts of normal microbiota and pathogenic microorganisms', 'Describe at least two different ways that antibiotics may kill bacteria', 'Understand the appropriateness of antimicrobial administration models such as outpatient parenteral antimicrobial therapy (OPAT)', and 'Actively engage self and others, including the patient/carer, in positively and constructively addressing conflict in a constructive manner'. Qualitative content analysis of open-ended responses identified 5 new descriptors (see Table 3). Five descriptors were amended in the light of qualitative feedback to form 8 additional descriptors (see Table 3). These amended descriptors, the 5 new descriptors, along with the four descriptors for which there was a lack of agreement (i.e. 17 descriptors in total), were taken forward to the round 2 survey. 
Insert Tables II and III about here

\section{Round 2 survey results}

Seventeen participants (89\%) responded to the second round. There were high levels of agreement for 16 of the 17 descriptors, with medians in the strong range of agreement (5-6 on the 6 point Likert scale) (see Table 4). The descriptor 'Describe how samples are processed/(i.e. susceptibility testing)' was viewed as less important (4.0 on the 6 point Likert scale). The strength of agreement was high for 13 Descriptors (IQR less than or equal to 1.5) but lower for 4 descriptors including; 'Describe the concepts of normal microbiota and pathogenic microorganism', 'Discuss the mechanisms by which microorganisms develop resistance to antimicrobials', 'Describe how samples are processed/ (i.e. susceptibility testing)', 'Actively engage self and others, including the patient/carer, in positively and constructively addressing conflict in a constructive manner.' National consensus was reached on 6 overarching competency statements (sub divided into 6 domains), and 55 individual descriptors essential for AMS by healthcare professionals (see Figure 3).

Insert Table IV and figure 3 about here

\section{DISCUSSION}

Through an interprofessional consensus process, core competencies in AMS were developed for UK healthcare professional undergraduate education. By starting with pre-defined competency 
statements and their associated descriptors, the traditional round 1 of a Delphi survey was unnecessary. The Delphi technique enabled panellists to reach consensus with consistent high levels of agreement, on 6 overarching competency statements representing the knowledge, skills, attitudes, and values that shape the judgements essential for AMS, and 55 individual descriptors, designed to reflect the level of experience of the learner and type of practice setting. To our knowledge these competencies represent the first of their kind; the integrative approach [32-33] adopted by the framework, enabling incorporation of descriptors throughout undergraduate healthcare professional education programmes, and encouraging learners to build up their knowledge and skills incrementally.

These competencies were developed to address a gap in AMS education for UK healthcare professional undergraduate programmes. They provide guidance for healthcare professionals and those working in new roles that support the delivery of healthcare (such as Nursing and Physician Associates), with regards to the array of direct care and medicines management activities for which an understanding and engagement with AMS is important. They also provide a foundation for registered health professionals (including pharmacists, nurses, midwives, and allied health professionals) who go onto prescribe after completing an additional post registration prescribing programme. This is important as there will be a greater need to strengthen AMS in the undergraduate education of these healthcare professionals, given recent proposals [42] to include generic prescribing competencies in these programmes, enabling less experienced healthcare professionals to access shortened post-registration prescribing courses. 
This competency framework will provide evidence of AMS in education programs and in learners' practice. The framework can also be used by those healthcare professionals who are able to prescribe on initial registration (i.e. doctors or dentists), although it is recognised that Expert panel members did not include representation from these groups and further work is required to gather their views to facilitate its adoption and integration into undergraduate degrees.

This competency framework has the potential to enhance the impact of AMS education and improve clinical practice and compliments the multi-professional approach adopted by national prescribing and AMS competencies [13-14]. Furthermore, the active participation in this work, of those who were involved in the development of these national competencies, supported alignment of the three resources. While the competency framework could serve as a resource for countries outside of the UK, their origin from the UK perspective leaves open the need for adaptation to other healthcare systems and consideration of any additional national and regional concerns. However, we hope that this framework will undergo further rigorous testing and refinement and further work is required to integrate and evaluate the impact of the framework in undergraduate healthcare professional programmes.

The framework provides a starting point for undergraduate healthcare professional education and may be applicable to post-graduate education. The descriptors represent a minimum 
standard and will be emphasized to a greater or lesser extent depending on professional roles, the experience of the learner and practice setting.

We encourage those involved in curriculum development across the healthcare professions to evaluate their current AMS educational content and adopt and test these competencies. The competencies can be incorporated into learning activities, that can be implemented through numerous learning opportunities integrated throughout undergraduate healthcare professional education. It is likely that this integration will differ between professions. Gaps or areas for improvement might be identified by mapping these competencies with existing curricula. The competency framework could also be used by regulators and professional bodies to inform proficiency standards and guidance.

\section{STUDY LIMITATIONS}

The main strength of the work is that it is based on responses from a national panel of defined experts, had a good response rate, and offers a framework of AMS competencies appropriate for undergraduate healthcare professional education. However, some limitations also need to be recognised. Firstly, only descriptors for which there was a lack of agreement were taken forward to the round 2 survey. Although this shortened the questionnaire and may have reduced attrition, this meant that stability of responses was not assessed across the two survey rounds. However, prior to survey 
round 2, a report of the collated results was shared with participants, who were also invited to provide further interpretation and feedback.

Secondly, our expert panel was determined through our approach to sampling, and although panel members were chosen to achieve a broad range of expertise, its composition does not reflect the full spectrum of professions involved in AMS for example, dentists and doctors. Therefore, our findings may not present an accurate picture of this population rather, they may represent the views of nurses, pharmacists, physiotherapists, and podiatrists.

Thirdly, although our sample size was in-line with recommendations for a homogenous sample [36], there were only small numbers of participants from each professional group, and so the views of sample participants may not be representative of the wider population which impinges upon the generalisation of results. However, larger samples have been reported to increase the difficulty of collecting data, reaching consensus, conducting analysis and verifying results [36]. Each of the survey rounds in this study received a good response rate, and consistently high levels of agreement was reached on competency statements and their associated descriptors.

\section{CONCLUSION}

Given the consistently high levels of agreement reached on competency statements and their associated descriptors, this competency framework should be used to direct undergraduate healthcare professional education, and those working in new clinical roles to support healthcare 
delivery, with regards to the array of activities for which an understanding and engagement with AMS is important. This will strengthen AMS in undergraduate healthcare professional education, which will become increasingly important as less experienced healthcare professionals are able to access shortened post-registration prescribing courses. Although the competencies target undergraduate education, they can also be used for continuing education. We encourage those involved in curriculum development to map this framework to existing curricula and adopt and test competencies and associated descriptors.

\section{ACKNOWLEDGEMENT}

We are grateful to Kathryn Yates, Alan Borthwick, Ian Reilly, Catriona Innes, and Val Ness who participated in this work as Expert Panel members. We are also grateful to the Nursing and Midwifery Council for their contribution to this work (Heather Bain, an Expert Panel member, being on secondment to the Nursing and Midwifery Council during the time this study was undertaken). We would also like to acknowledge Discover Research and Design Ltd who assisted with the data collection and analysis.

DECLARATION OF INTEREST 
Declarations of interest: none

\section{FUNDING SOURCE}

This research did not receive any specific grant from funding agencies in the public, commercial, or not-for-profit sectors.

\section{CONTRIBUTORSHIP STATEMENT}

MC made substantial contributions to the concept and design of the work, and the acquisition, analysis and interpretation of the data. RL made substantial contributions to the design of the work, and the acquisition and interpretation of the data. $\mathrm{KH}, \mathrm{RD}, \mathrm{MW}, \mathrm{GM}, \mathrm{SR}, \mathrm{EC}$, contributed to the acquisition and interpretation of the data. HB, PW, MF, AB, DS, JS, AT, RG, DAO, DG, NR, $\mathrm{JM}, \mathrm{AC}, \mathrm{JB}, \mathrm{CD}$ (all Expert Panel members) contributed to the interpretation of the data. All authors contributed to drafting and/or revising this manuscript, approved the final version of the paper, and agreed to be accountable for all aspects of the work. 


\section{REFERENCES}

1. WHO. Antimicrobial resistance Fact sheet No. 194. 2017.

http://www.who.int/mediacentre/factsheets/antibiotic-resistance/en/

2. European Commission - Fact Sheet. New EU Action Plan on Antimicrobial Resistance Questions and answers: Brussels. 2017

3. Fishman, N. Antimicrobial stewardship. American Journal of Infection Control 2006, 34(5 suppl 1), S55-S63.

4. Doron S, Davidson LE. Antimicrobial stewardship...Mayo Clin Proc.2011 Nov;86(11):1113-23

5. Gerding DN. The search for good antimicrobial stewardship. Jt Comm J Qual Improv. 2001;27(8):403-404

6. WHO. Global action plan on antimicrobial resistance, 2016 http://apps.who.int/iris/bitstream/10665/193736/1/9789241509763 eng.pdf?ua=1

7. Castro-Sánchez, E., Drumright, L.N., Gharbi, M., Farrell, S., Holmes, A.H. Mapping Antimicrobial Stewardship in Undergraduate Medical, Dental, Pharmacy, Nursing and Veterinary Education in the United Kingdom. PLOS ONE 2016,11(2): e0150056. doi:10.1371/journal.pone.0150056

8. Luther VP, Shnekendorf R, Abbo LM, et al. Antimicrobial Stewardship Training for Infectious Diseases Fellows: Program Directors Identify a Curriculum Need. Clin Infect Dis. 2018 Apr 16. doi: 10.1093/cid/ciy332

9. Gruppen, L.D., Mangrulkar, R.S., Kolars, J.C. The promise of competency-based education in the health professions for improving global health. Human Resources for Health 2012,10(1),43.

10. Rathert, C., Wyrwich, M.D., Boren, S.A. Patient-centered care and outcomes: A systematic review of the literature. Medical Care Research and Review 2012, 70(4), 351-379. doi: 10.1177/ 1077558712465774. 
11. Gachoud, D., Albert, M., Kuper, A., Stroud, L., Reeves, S. Meanings and perceptions of patient-centredness in social work, nursing and medicine: a comparative study. Journal of Interprofessional Care 2012, 26, 484-490.

12. Pereira NR, Castro-Sanchez E, Nathwani D. How can Multi-Professional Education Support Better Stewardship? Infect Dis Rep.2017 Mar 30;9(1):6917.

13. RPS. A competency framework for all prescribers. London: RPS. 2016

14. PHE. Antimicrobial prescribing and stewardship competencies. London: PHE. 2013

15. DoH: Improving patient's access to medicines: A guide to implementing nurse and pharmacist independent prescribing within the NHS in England. London: DoH 2006

16. Department of Health Advisory Committee on Antimicrobial Resistance and Healthcare Associated Infection (ARHAI). Antimicrobial Stewardship: "Start Smart-Then Focus" Guidance for antimicrobial stewardship in hospitals (England). 2011.

17. RPS. Infection and antimicrobial stewardship. Expert professional practice curriculum. London: London: RPS 2014

18. General Pharmaceutical Council. Standards for the initial education and training of pharmacy technicians. GPC; England. 2017

19. GPC. Future pharmacists Standards for the initial education and training of pharmacists, GPC; England. 2011

20. NMC. Standards for pre-registration nursing education, NMC: London. 2010

21. HCPC. Standards of education and training. HCPC: London. 2017

22. DHSS. https://www.gov.uk/government/news/nursing-associate-role-offers-newroute-into-nursing, 2005

23. HEE. Workforce plan for England. HEE: London. 2014

24. Reeves S, Pelone F, Harrison R, Goldman J, Zwarenstein M. Interprofessional collaboration to improve professional practice and healthcare outcomes. Cochrane Database Syst Rev 2017. CD000072. doi: 10.1002/14651858.CD000072.pub3

25. Reeves S, Palaganas J, Zierler B. An Updated Synthesis of Review Evidence of Interprofessional Education. J Allied Health 2017; 46(1):56-61.

26. Keeney, S., Hasson, F., McKenna, H. The Delphi technique in nursing and health research. Chichester, West Sussex: Wiley-Blackwell. 2011.

27. Hasson, F., Keeney, S., McKenna, H. Research guidelines for the Delphi survey technique. J Adv Nurs 2000, 32:1008-15 
28. Day, J., Bobeva, M. A generic toolkit for the successful management of Delphi studies. Electron J Bus Res Methodol 2005, 3:103-16.

29. CIHC. A national interprofessional competency framework. University of British Columbia: Vancouver. 2010

30. Hsu C, Sandford BA. Minimizing non-response in the Delphi process: how to respond to non-response. Pract Assess Res Eval 2007;12 http://pareonline.net/getvn.asp?v=12\&n=17 URL(accessed $13^{\text {th }}$ June 2018)

31. Courtenay, M., Castro-Sánchez, E. et al. Defining antimicrobial stewardship competencies for undergraduate health professionaleducati on in the United Kingdom: A study protocol. J Interprof Care. 2018 Apr 16:1-3. doi: 10.1080/13561820.2018.1463200.

32. Peyser, A., Gerard, F-M., \& Roegiers, X. Implementing a pedagogy of integration: Some thoughts based on a textbook elaboration experience in Vietnam. Planning and changing 2006, 37(1/2), 37-55./2), 37-55.

33. Roegiers, $X$. Curricular reforms guide schools: but, where to? Curriculum change and competency-based approaches: A worldwide perspective. Prospects 2007, 37(2), 155186.

34. Baker J, Lovell K, Harris N. How expert are the experts? An exploration of the concept of 'expert' within Delphi panel techniques. Nurse Res 2006;14:59-70

35. Trevelyan, EG., Robinson, N. Delphi methodology in health research: how to do it? European Journal of Integrative Medicine. 2015, 7, 423-428

36. Skulmoski, GJ., Hartman, FT., Krahn, J. The Delphi methods for graduate research. J Inf Technol Educ. 2007 6:1-21.

37. Boulkedid, R, Abdoul, $H$, Loustau, $M$, Sibony, $O$, Alberti, C. Using and reporting the Delphi method for selecting healthcare quality indicators: a systematic review, PLoS One 6 (6) (2011) e20476

38. Stark, D., Bielack, S., Brugieres, L., et al. 2016. Teenagers and young adults with cancer in Europe: from national programmes to a European integrated coordinated project. Eur J Cancer Care 2016, 25(3):419-27

39. Taylor RM, Feltbower RG, Aslam N, et al (2016). Modified international eDelphi survey to define healthcare professional competencies for working with teenagers and young adults with cancer. BMJ Open 6:e011361. doi:10.1136/bmjopen-2016- 011361 
40. Shepherd, V, Wood, F., Hood, K. Establishing a set of research priorities in care homes for older people in the UK: a modified Delphi consensus study with care home staff. Age and Ageing 2017; 46: 284-290

41. Braun, V., \& Clarke, V. Using thematic analysis in psychology. Qualitative research in psychology 2006, 3(2), 77-101

42. NMC. Consultation on prescribing and standards for medicines management. NMC, London. 2017

Table I - Expert panel details

\begin{tabular}{|c|c|c|c|c|c|c|}
\hline Expert Panel & \multicolumn{3}{|c|}{ Round 1 n=19 (90\%) } & \multicolumn{3}{c|}{ Round 2 n=17 (89\%) } \\
\hline Professional group & $\begin{array}{c}\text { Prescribing } \\
\text { and } \\
\text { medicines } \\
\text { management } \\
\text { practice }\end{array}$ & $\begin{array}{c}\text { Prescribing } \\
\text { and } \\
\text { medicines } \\
\text { management } \\
\text { education }\end{array}$ & $\begin{array}{c}\text { Antimicrobial } \\
\text { prescribing } \\
\text { and } \\
\text { stewardship }\end{array}$ & $\begin{array}{c}\text { Prescribing } \\
\text { and } \\
\text { medicines } \\
\text { management } \\
\text { practice }\end{array}$ & $\begin{array}{c}\text { Prescribing } \\
\text { and } \\
\text { medicines } \\
\text { management } \\
\text { education }\end{array}$ & $\begin{array}{c}\text { Antimicrobial } \\
\text { prescribing } \\
\text { and } \\
\text { stewardship }\end{array}$ \\
\hline Nurse/Midwife & 4 & 1 & 3 & 3 & 1 & 2 \\
\hline Pharmacist & 1 & 3 & 3 & 1 & 3 & 3 \\
\hline Physiotherapist & 1 & 0 & 0 & 1 & 0 & 0 \\
\hline Podiatrist & 2 & 1 & 0 & 2 & 1 & 0 \\
\hline Total & $\mathbf{8}$ & $\mathbf{5}$ & $\mathbf{6}$ & $\mathbf{7}$ & $\mathbf{5}$ & $\mathbf{5}$ \\
\hline
\end{tabular}


Table II - Round one survey responses

\begin{tabular}{|c|l|l|}
\hline Domain One: Infection prevention and control & Median & IQR \\
\hline Describing what a micro-organism is & 6 & 1 \\
\hline $\begin{array}{l}\text { Describing the different types of organisms that may cause } \\
\text { infections. }\end{array}$ & 6 & 1 \\
\hline Explaining what an antimicrobial resistant organism is & 6 & 0.5 \\
\hline $\begin{array}{l}\text { Describe the concepts of normal microbiota and pathogenic } \\
\text { microorganisms }\end{array}$ & 5 & 2.0 \\
\hline Explaining the 'Chain of Infection'. & 5.5 & 1.5 \\
\hline $\begin{array}{l}\text { Defining the components required for infection transmission } \\
\text { (i.e. presence of an organism, route of transmission of the } \\
\text { organism from one person to another, a host who is } \\
\text { susceptible to infection). }\end{array}$ & 5.5 & 1.0 \\
\hline $\begin{array}{l}\text { Describing the routes of transmission of infectious organisms } \\
\text { i.e., Contact, Droplet, Airborne routes. }\end{array}$ & 6 & 1.0 \\
\hline Present and recognize the characteristics of a susceptible host. & 5.5 & 1.0 \\
\hline Demonstrate an understanding of the Importance of Surveillance & 5.0 & 1.0 \\
\hline $\begin{array}{l}\text { Describe how vaccines can prevent infections in susceptible } \\
\text { persons. }\end{array}$ & 5 & 1.0 \\
\hline $\begin{array}{l}\text { Demonstrate the application of standard precautions in healthcare } \\
\text { environments }\end{array}$ & 5.5 & 0.0 \\
\hline $\begin{array}{l}\text { Apply appropriate policies/procedures and guidelines when } \\
\text { collecting and handling specimens. }\end{array}$ & 6 & 1.0 \\
\hline $\begin{array}{l}\text { Apply policies, procedures and guidelines relevant to infection } \\
\text { control when presented with infection control cases and situations }\end{array}$ & 6 & 1.0 \\
\hline $\begin{array}{l}\text { Implement work practices that reduce risk of infection (such } \\
\text { as taking appropriate immunization or not coming to work } \\
\text { when sick to ensure patient and other healthcare worker } \\
\text { protection). }\end{array}$ & 6 & 0.0 \\
\hline $\begin{array}{l}\text { Appreciate that healthcare workers have the accountability } \\
\text { and obligation to follow infection control protocols as part of } \\
\text { their contract of employment. }\end{array}$ & 6 & 0.0 \\
\hline $\begin{array}{l}\text { Act as a role model to healthcare workers and members of the } \\
\text { public by adhering to infection prevention and control } \\
\text { principles. }\end{array}$ & 6 & 1.25 \\
\hline Domain Two: Antimicrobials and antimicrobial resistance & 6 \\
\hline Recognise the symptoms of infection. & 6 \\
\hline
\end{tabular}




\begin{tabular}{|c|c|c|}
\hline $\begin{array}{l}\text { Describe at least two different ways that antimicrobials may } \\
\text { kill bacteria. }\end{array}$ & 5 & 2.0 \\
\hline $\begin{array}{l}\text { Discuss how inappropriate antimicrobial use (including non- } \\
\text { adherence to treatment regime) may lead to antimicrobial } \\
\text { resistance }\end{array}$ & 6 & 1.0 \\
\hline $\begin{array}{l}\text { Identify approaches to support optimal prescribing of } \\
\text { antimicrobials }\end{array}$ & 6 & 1.0 \\
\hline \multicolumn{3}{|l|}{$\begin{array}{l}\text { Domain Three: The diagnosis of infection and the use of } \\
\text { antimicrobials }\end{array}$} \\
\hline $\begin{array}{l}\text { Explain how microbiology samples may aid diagnosis of } \\
\text { infection }\end{array}$ & 6 & 1.0 \\
\hline $\begin{array}{l}\text { Discuss the use of rapid point-of-care diagnostic testing in } \\
\text { infection diagnosis }\end{array}$ & 4.5 & 1.0 \\
\hline $\begin{array}{l}\text { Describe how and demonstrate (following local procedures) } \\
\text { the appropriate taking of samples }\end{array}$ & 6 & 1.25 \\
\hline $\begin{array}{l}\text { Describe how samples are processed (i.e. susceptibility } \\
\text { testing), and interpret microbiology results/reports from the } \\
\text { laboratory at a basic level }\end{array}$ & 5 & 1.0 \\
\hline $\begin{array}{l}\text { Explain why self-limiting bacterial or viral infections are } \\
\text { unlikely to benefit from antimicrobials }\end{array}$ & 6 & 1.0 \\
\hline $\begin{array}{l}\text { Describe and demonstrate the self-management strategies } \\
\text { required to treat self-limiting infections (i.e. analgesia /rest } \\
\text { /fluids) }\end{array}$ & 6 & 1.0 \\
\hline $\begin{array}{l}\text { Understand the importance of following local antimicrobial } \\
\text { policies (i.e. their development is based on local resistance } \\
\text { patterns) and follow these policies in practice }\end{array}$ & 6 & 0.0 \\
\hline $\begin{array}{l}\text { Explain the importance of documenting the indications for an } \\
\text { antimicrobial (i.e the route by which it is administered, its } \\
\text { duration, dose, dose interval, and review date), in clinical } \\
\text { notes and demonstrate this in practice }\end{array}$ & 6 & 0.25 \\
\hline $\begin{array}{l}\text { Demonstrate an understanding of the factors that need to be } \\
\text { considered when choosing an antimicrobial (including site of } \\
\text { infection and type of bacteria likely to cause an infection at a } \\
\text { particular site) }\end{array}$ & 6 & 1.0 \\
\hline $\begin{array}{l}\text { Describe broad spectrum and narrow spectrum antimicrobials } \\
\text { and the contribution of broad spectrum antimicrobials to } \\
\text { AMR }\end{array}$ & 5.5 & 1.0 \\
\hline $\begin{array}{l}\text { Present and be able to recognise the common side effects } \\
\text { associated with commonly administered antimicrobials }\end{array}$ & 6 & 1.0 \\
\hline
\end{tabular}




\begin{tabular}{|c|c|c|}
\hline $\begin{array}{l}\text { Demonstrate an understanding of why documenting a patient } \\
\text { allergy to an antimicrobial is important }\end{array}$ & 6 & 1.25 \\
\hline $\begin{array}{l}\text { Explain why it is important to consider certain physiological } \\
\text { conditions (such as renal function) in patients who receive an } \\
\text { antimicrobial }\end{array}$ & 6 & 1.0 \\
\hline Describe what is meant by delayed prescribing & 5 & 1.0 \\
\hline \multicolumn{3}{|l|}{ Domain Four: Antimicrobial prescribing practice } \\
\hline $\begin{array}{l}\text { Explain how you would recognise and manage sepsis and why } \\
\text { it is important to use local guidelines to initiate prompt } \\
\text { effective antimicrobial treatment in patients with life } \\
\text { threatening infections }\end{array}$ & 6 & 0.0 \\
\hline $\begin{array}{l}\text { Describe why, and how, it is important to switch from IV } \\
\text { antimicrobials to oral therapy }\end{array}$ & 6 & 0.5 \\
\hline $\begin{array}{l}\text { Understand the appropriateness of antimicrobial } \\
\text { administration models such as outpatient parenteral } \\
\text { antimicrobial therapy (OPAT) }\end{array}$ & 5 & 2.0 \\
\hline $\begin{array}{l}\text { Demonstrate an understanding of the rationale and use of } \\
\text { perioperative prophylactic antibiotics to prevent surgical site } \\
\text { infection }\end{array}$ & 5 & 1.0 \\
\hline $\begin{array}{l}\text { Discuss factors that can influence antimicrobial prescribing } \\
\text { and the implications for antimicrobial stewardship } \\
\text { programmes }\end{array}$ & 6 & 1.25 \\
\hline Domain Five: Person centred care & 6 & \\
\hline $\begin{array}{l}\text { Support participation of patients/carers, as integral partners } \\
\text { when planning/delivering their care }\end{array}$ & 6 & 0.25 \\
\hline $\begin{array}{l}\text { Share information with patients/carer in a respectful manner and } \\
\text { in such a way that is understandable, encourages discussion, and } \\
\text { enhances participation in decision-making }\end{array}$ & 6 & 1.0 \\
\hline $\begin{array}{l}\text { Ensure that appropriate education and support is provided by } \\
\text { learners to patients/carer, and others involved with their care or } \\
\text { service; }\end{array}$ & 6 & 0.25 \\
\hline $\begin{array}{l}\text { Listen respectfully to the expressed needs of all parties in } \\
\text { shaping and delivering care or services. }\end{array}$ & 6 & 0.25 \\
\hline $\begin{array}{l}\text { Discuss patient/carer expectations or demands of } \\
\text { antimicrobials and the need to use antimicrobials } \\
\text { appropriately. }\end{array}$ & 6 & 0.0 \\
\hline Domain Six: Interprofessional collaborative practice & & \\
\hline
\end{tabular}




\begin{tabular}{|l|l|l|}
\hline $\begin{array}{l}\text { Demonstrate an understanding of the roles, responsibilities, and } \\
\text { competencies of other health professionals involved in } \\
\text { antimicrobial treatment policy decisions }\end{array}$ & 5 & 1.0 \\
\hline $\begin{array}{l}\text { Explain why it is important that healthcare professionals, } \\
\text { involved in the delivery of antimicrobial therapy, have a common } \\
\text { understanding of antimicrobial treatment policy decisions, the } \\
\text { quality of antimicrobial use, and effective patient/client outcomes }\end{array}$ & 5 & 1.0 \\
\hline $\begin{array}{l}\text { Establish collaborative communication principles and actively } \\
\text { listen to other professionals and patients/carer }\end{array}$ & 5.5 & 1.0 \\
\hline $\begin{array}{l}\text { Communicate effectively to ensure common understanding of } \\
\text { care decisions }\end{array}$ & 6 & 0.5 \\
\hline $\begin{array}{l}\text { Develop trusting relationships with patients /carer and other } \\
\text { health/social care professionals }\end{array}$ & 6 & 1.0 \\
\hline $\begin{array}{l}\text { Effectively use information and communication technology to } \\
\text { improve interprofessional patient -centred care }\end{array}$ & 5.5 & 1.0 \\
\hline $\begin{array}{l}\text { Actively engage self and others, including the patient/carer, in } \\
\text { positively and constructively addressing conflict in a constructive } \\
\text { manner }\end{array}$ & 5 & 2.0 \\
\hline
\end{tabular}

*Green - High level of agreement that descriptor is not important i.e. median less than 5

${ }^{*}$ Grey - lack of agreement i.e. IQR more than 1.5 
Table III - New and amended descriptors

\begin{tabular}{|l|}
\hline New Descriptors \\
\hline Domain One: Infection prevention and control \\
\hline $\begin{array}{l}\text { Demonstrate knowledge and awareness of international /national strategies on } \\
\text { infection prevention and control and antimicrobial resistance such as Global Action } \\
\text { Plan for AMR \& Save Lives- Clean Your Hands http://www.who.int/gpsc/5may/en/ } \\
\text { and the UK Governments 5-year Antimicrobial Resistance Strategy }\end{array}$ \\
\hline Domain Two: Antimicrobials and antimicrobial resistance \\
\hline $\begin{array}{l}\text { Discuss the mechanisms by which microorganisms develop resistance to } \\
\text { antimicrobials }\end{array}$ \\
\hline Domain Three: The diagnosis of infection and the use of antimicrobials \\
\hline $\begin{array}{l}\text { Explain why an accurate diagnosis, based on history and laboratory tests, is essential } \\
\text { when determining if a patient has an allergy to an antimicrobial }\end{array}$ \\
\hline Domain Four: Antimicrobial prescribing practice \\
\hline Describe the national guidance on completion of a course of antimicrobials \\
Describe some of the medicines with which antimicrobials can sometimes interact \\
Describe why it is important to use local guidelines to initiate prompt effective \\
\hline Amtimicrobial treatment in patients with life threatening infections \\
\hline Domain Three: The diagnosis of infection and the use of antimicrobials \\
\hline Describe how samples are processed/ (i.e. susceptibility testing) \\
\hline Domain Six: Interprofessional collaborative practice \\
\hline Domain Four: Antimicrobial prescribing practice \\
\hline Explain how you would recognise and manage sepsis \\
\hline
\end{tabular}


Explain why it is important that healthcare professionals, involved in the delivery of antimicrobial therapy (including the prescription, delivery and supply), have a common understanding of antimicrobial treatment policy decisions, the quality of antimicrobial use, and effective patient/client outcomes

Establish collaborative communication principles and actively listen to other professionals and patients/carer involved in the delivery of antimicrobial therapy 
Table IV - Round 2 survey responses

\begin{tabular}{|c|c|c|}
\hline Domain One: Infection prevention and control & Median & IQR \\
\hline $\begin{array}{l}\text { Demonstrating knowledge and awareness of international } \\
\text { /national strategies on infection prevention and control and } \\
\text { antimicrobial resistance such as Global Action Plan for AMR \& } \\
\text { Save Lives- Clean Your Hands } \\
\text { http://www.who.int/gpsc/5may/en/ and the UK Governments 5- } \\
\text { year Antimicrobial Resistance Strategy }\end{array}$ & 5.0 & 1.25 \\
\hline $\begin{array}{l}\text { Describe the concepts of normal microbiota and pathogenic } \\
\text { microorganisms }\end{array}$ & 5.0 & 2.0 \\
\hline \multicolumn{3}{|l|}{ Domain Two: Antimicrobials and antimicrobial resistance } \\
\hline $\begin{array}{l}\text { Discuss the mechanisms by which microorganisms develop } \\
\text { resistance to antimicrobials }\end{array}$ & 5.0 & 2.0 \\
\hline $\begin{array}{l}\text { Describe at least two different ways that antimicrobials may kill } \\
\text { bacteria. }\end{array}$ & 5.0 & 1.0 \\
\hline \multicolumn{3}{|l|}{$\begin{array}{l}\text { Domain Three: The diagnosis of infection and the use of } \\
\text { antimicrobials }\end{array}$} \\
\hline Describe how samples are processed/ (i.e. susceptibility testing) & 4.0 & 2.25 \\
\hline $\begin{array}{l}\text { Interpret microbiology results/reports from the laboratory at a } \\
\text { basic level }\end{array}$ & 6.0 & 1.0 \\
\hline $\begin{array}{l}\text { Explain why an accurate diagnosis, based on history and } \\
\text { laboratory tests, is essential when determining if a patient has an } \\
\text { allergy to an antimicrobial }\end{array}$ & 6.0 & 1.0 \\
\hline \multicolumn{3}{|l|}{ Domain Four: Antimicrobial prescribing practice } \\
\hline Explain how you would recognise and manage sepsis & 6.0 & 0.0 \\
\hline $\begin{array}{l}\text { Describe why it is important to use local guidelines to initiate } \\
\text { prompt effective antimicrobial treatment in patients with life } \\
\text { threatening infections }\end{array}$ & 6.0 & 0.0 \\
\hline Describe why it is important to switch from IV antimicrobials to & 6.0 & 0.0 \\
\hline
\end{tabular}




\begin{tabular}{|l|l|l|}
\hline oral therapy & & \\
\hline Describe how to switch from IV antimicrobials to oral therapy & 6.0 & 1.0 \\
\hline $\begin{array}{l}\text { Describe the national guidance on completion of a course of } \\
\text { antimicrobials }\end{array}$ & 6.0 & 1.0 \\
\hline $\begin{array}{l}\text { Describe some of the medicines with which antimicrobials can } \\
\text { sometimes interact }\end{array}$ & 6.0 & 1.0 \\
\hline $\begin{array}{l}\text { Understand the appropriateness of antimicrobial administration } \\
\text { models such as outpatient parenteral antimicrobial therapy } \\
\text { (OPAT) }\end{array}$ & 5.0 & 1.25 \\
\hline Domain Six: Interprofessional collaborative practice & $\begin{array}{l}\text { Explain why it is important that healthcare professionals, involved } \\
\text { in the delivery of antimicrobial therapy (including the } \\
\text { prescription, delivery and supply), have a common understanding } \\
\text { of antimicrobial treatment policy decisions, the quality of } \\
\text { antimicrobial use, and effective patient/client outcomes }\end{array}$ & 5.5 \\
\hline $\begin{array}{l}\text { Establish collaborative communication principles and actively } \\
\text { listen to other professionals and patients/carer involved in the } \\
\text { delivery of antimicrobial therapy }\end{array}$ & 6.0 & 1.0 \\
\hline $\begin{array}{l}\text { Actively engage self and others, including the patient/carer, in } \\
\text { positively and constructively addressing conflict in a constructive } \\
\text { manner }\end{array}$ & 5.5 & 2.0 \\
\hline
\end{tabular}

${ }^{*}$ Green - High level of agreement that descriptor is not important i.e. median less than 5.

*Grey - lack of agreement i.e. IQR more than 1.5 
Figure 1 - Competency domains and descriptors

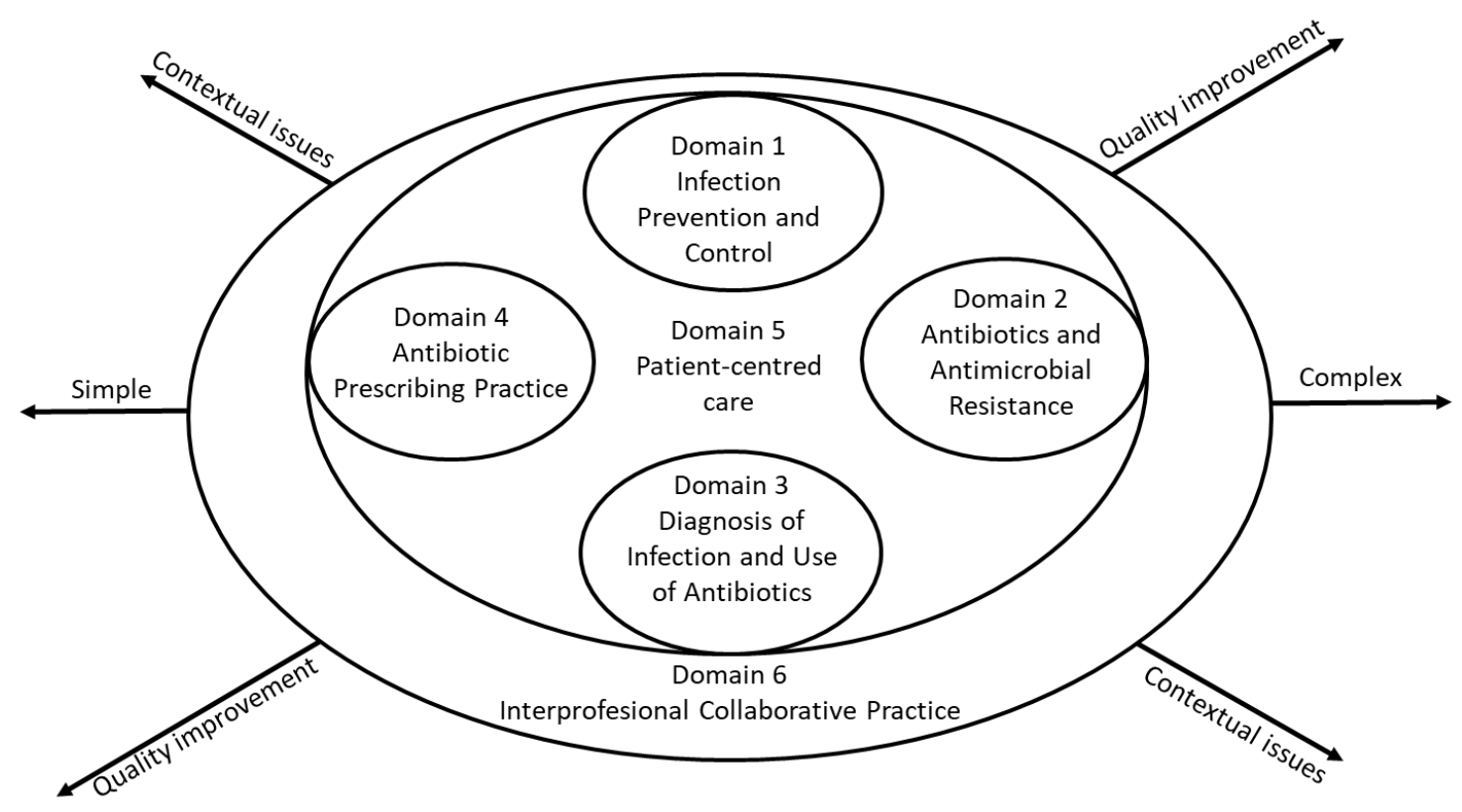


Figure 2 - Summary of the Delphi process

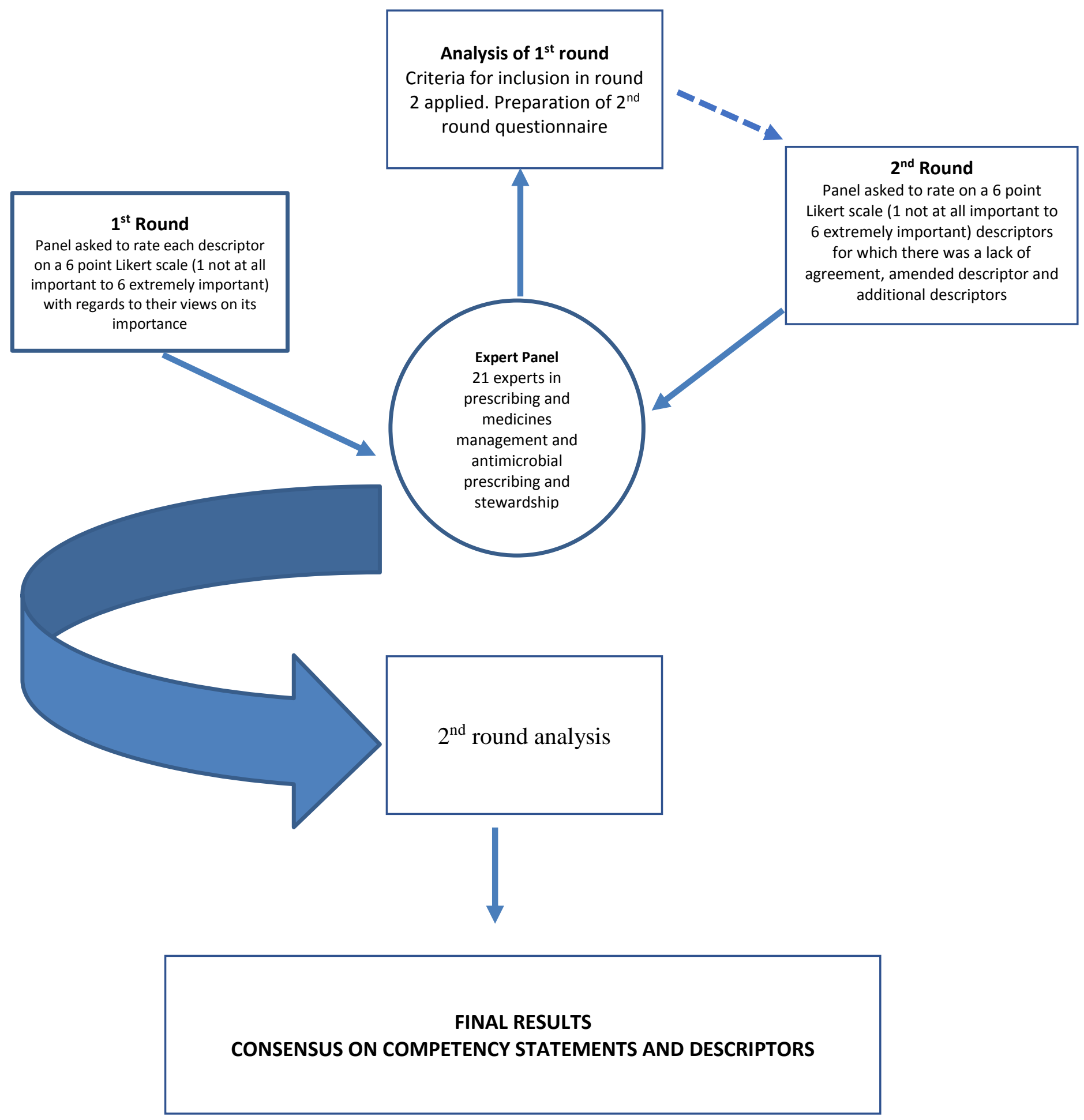


Figure 3 - Antimicrobial stewardship framework

DOMAIN ONE: INFECTION PREVENTION AND CONTROL

COMPETENCY STATEMENT: All qualified health care professionals must understand the core knowledge underpinning infection prevention and control, and use this knowledge appropriately to prevent the spread of infection.

Descriptors

To support antimicrobial stewardship learners must demonstrate infection prevention and control by:

1. Describing what a micro-organism is

2. Describing the different types of organisms that may cause infections

3. Explaining what an antimicrobial resistant organism is

4. Explaining the 'Chain of Infection'.

5. Defining the components required for infection transmission (i.e. presence of an organism, route of transmission of the organism from one person to another, a host who is susceptible to infection).

6. Describing the routes of transmission of infectious organisms i.e., Contact, Droplet, Airborne routes.

7. Present and recognize the characteristics of a susceptible host.

8. Demonstrate an understanding of the Importance of Surveillance.

9. Describe how vaccines can prevent infections in susceptible persons.

10. Demonstrate the application of standard precautions in healthcare environments.

11. Apply appropriate policies/procedures and guidelines when collecting and handling specimens.

12. Apply policies, procedures and guidelines relevant to infection control when presented with infection control cases and situations.

13. Implement work practices that reduce risk of infection (such as taking appropriate immunization or not coming to work when sick to ensure patient and other healthcare worker protection).

14. Appreciate that healthcare workers have the accountability and obligation to follow infection control protocols as part of their contract of employment.

15. Act as a role model to healthcare workers and members of the public by adhering to infection prevention and control principles.

16. Demonstrating knowledge and awareness of international /national strategies on infection prevention and control and antimicrobial resistance such as Global Action Plan for AMR \& Save Lives- Clean Your Hands http://www.who.int/gpsc/5may/en/ and 
the UK Governments 5-year Antimicrobial Resistance Strategy

\section{DOMAIN TWO: ANTIMICROBIALS AND ANTIMICROBIAL RESISTANCE}

COMPETENCY STATEMENT: All qualified health care professionals need to understand the core knowledge underpinning the concept of antimicrobial resistance and use this knowledge to help prevent antimicrobial resistance.

\section{Descriptors}

To support antimicrobial stewardship learners must be able to:

1. Recognise the symptoms of infection.

2. Describe at least two different ways that antimicrobials may kill bacteria.

3. Discuss how inappropriate antimicrobial use (including non-adherence to treatment regime) may lead to antimicrobial resistance

4. Identify approaches to support optimal prescribing of antimicrobials

5. Describe at least two different ways that antimicrobials may kill bacteria

\section{DOMAIN THREEE: THE DIAGNOSIS OF INFECTION AND THE USE OF ANTIBIOTICS}

COMPETENCY STATEMENT: All qualified health care professionals need to demonstrate knowledge in how infections are diagnosed and the appropriate use of antimicrobials, and use this knowledge appropriately to support the accurate diagnosis of infection and the appropriate use of antimicrobials.

\section{Descriptors}

To support antimicrobial stewardship, learners must be able to:

1. Explain how microbiology samples may aid diagnosis of infection

2. Describe how and demonstrate (following local procedures) the appropriate taking of samples

3. Interpret microbiology results/reports from the laboratory at a basic level

4. Explain why self-limiting bacterial or viral infections are unlikely to benefit from antimicrobials

5. Describe and demonstrate the self-management strategies required to treat selflimiting infections (i.e. analgesia /rest /fluids)

6. Understand the importance of following local antimicrobial policies (i.e. their development is based on local resistance patterns) and follow these policies in practice

7. Explain the importance of documenting the indications for an antimicrobial (i.e the route by which it is administered, its duration, dose, dose interval, and review date), in clinical notes and demonstrate this in practice 
8. Demonstrate an understanding of the factors that need to be considered when choosing an antimicrobial (including site of infection and type of bacteria likely to cause an infection at a particular site)

9. Describe broad spectrum and narrow spectrum antimicrobials and the contribution of broad spectrum antimicrobials to AMR

10. Present and be able to recognise the common side effects associated with commonly administered antimicrobials

11. Demonstrate an understanding of why documenting a patient allergy to an antimicrobial is important

12. Explain why it is important to consider certain physiological conditions (such as renal function) in patients who receive an antimicrobial

13. Describe what is meant by delayed prescribing

14. Explain why it is essential that an accurate diagnosis of an allergy to an antimicrobial is based on history and laboratory tests.

\section{DOMAIN FOUR: ANTIMICROBIAL PRESCRIBING PRACTICE}

COMPETENCY STATEMENT: All qualified health care professionals need to be aware of how antimicrobials are used in practice in terms of their dose, timing, duration and appropriate route of administration, and apply this knowledge as part of their routine practice as follows:

\section{Descriptors}

To support antimicrobial stewardship, learners must be able to:

1. Explain how you would recognise and manage sepsis

2. Describe why it is important to use local guidelines to initiate prompt effective antimicrobial treatment in patients with life threatening infections

3. Describe why it is important to switch from IV antimicrobials to oral therapy

4. Describe how to switch from IV antimicrobials to oral therapy

5. Understand the appropriateness of antimicrobial administration models such as outpatient parenteral antimicrobial therapy (OPAT)

6. Demonstrate an understanding of the rationale and use of perioperative prophylactic antimicrobials to prevent surgical site infection

7. Discuss factors that can influence antimicrobial prescribing and the implications for antimicrobial stewardship programmes

8. Describe the national guidance on completion of a course of antimicrobials

9. Describe some of the medicines with which antimicrobials can sometimes interact 


\section{DOMAIN FIVE: PERSON CENTRED CARE}

COMPETENCY STATEMENT: All qualified health care professionals must seek out, integrate and value as a partner the input and engagement of the patient /carer in designing and implementing care

Descriptors: To support antimicrobial stewardship that is patient centred, learners need to:

1) Support participation of patients/carers, as integral partners when planning/delivering their care

2) Share information with patients/carer in a respectful manner and in such a way that is understandable, encourages discussion, and enhances participation in decision-making

3) Ensure that appropriate education and support is provided by learners to patients/carer, and others involved with their care or service;

4) Listen respectfully to the expressed needs of all parties in shaping and delivering care or services.

5) Discuss patient/carer expectations or demands of antimicrobials and the need to use antimicrobials appropriately.

\section{DOMAIN SIX: INTERPROFESSIONAL COLLABORATIVE PRACTICE}

COMPETENCY STATEMENT: All qualified health care professionals need to understand how different professions collaborate in relation to how they contribute to AS.

Descriptors: To support AS learners are able to:

1) Demonstrate an understanding of the roles, responsibilities, and competencies of other health professionals involved in antimicrobial treatment policy decisions

2) Explain why it is important that healthcare professionals, involved in the delivery of antimicrobial therapy (including the prescription, delivery and supply), have a common understanding of antimicrobial treatment policy decisions, the quantity of antimicrobial use, and effective patient/client outcomes

3) Establish collaborative communication principles and actively listen to other professionals and patients/carer involved in the delivery of antimicrobial therapy

4) Communicate effectively to ensure common understanding of care decisions

5) Develop trusting relationships with patients /carer and other health/social care professionals

6) Effectively use information and communication technology to improve interprofessional patient -centred care 


\section{Legends}

Table I - Expert panel details

Table II - Round one survey responses

Table III - New and amended descriptors

Table IV - Round 2 survey responses

Figure 1 - Competency domains and descriptors

Figure 2 - Summary of the Delphi process

Figure 3 - Antimicrobial stewardship framework 